\title{
The optimal decoction time of Yinqiao Powder on inhibit influenza A virus FM1 in mice.
}

\author{
Liang Chang1, Jinchuan Tan², Fang Liu ${ }^{1}$, Guangjie Liu' ${ }^{1}$, Yaxian Liu ${ }^{1}$, Bingjie Huo ${ }^{1,3 *}$ \\ ${ }^{1}$ Department of Traditional Chinese Medicine, Fourth Hospital of Hebei Medical University, Shijiazhuang, PR China \\ ${ }^{2}$ Department of Nephrology, Traditional Chinese Medicine of Hebei province hospital, Shijiazhuang, PR China \\ ${ }^{3}$ Tianjin University of Traditional Chinese Medicine, PR China
}

\begin{abstract}
Background: Yinqiao Powder (YQP) is administered in Traditional Chinese Medicine (TCM) for febrile infectious diseases and has been demonstrated to fight the prevalence of influenza.

Objective: The present study aimed to identify the optimal decoction time of YQP on inhibit influenza A virus FM1 and investigate the molecular mechanisms of different decocting time YQP.

Methods: The male BALB/c mice were made into pneumonia model of influenza A virus FM1. They were randomly assigned to twelve groups: blank control group, model control group, tamiflu (27.5 $\mathrm{mg} / \mathrm{Kg}$ ) group, 3 minutes YQP (High-dose group $30 \mathrm{~g} / \mathrm{Kg} \cdot \mathrm{d}$, Middle-dose group $15 \mathrm{~g} / \mathrm{Kg} \cdot \mathrm{d}$, and Low-dose group $7.5 \mathrm{~g} / \mathrm{Kg} \cdot \mathrm{d}$ ) groups, 6 minutes YQP (High-dose group $30 \mathrm{~g} / \mathrm{Kg} \cdot \mathrm{d}$, Middle-dose group $15 \mathrm{~g} / \mathrm{Kg} \cdot \mathrm{d}$, and Low-dose group $7.5 \mathrm{~g} / \mathrm{Kg} \cdot \mathrm{d}$ ) groups, and 12 minutes YQP (High-dose group $30 \mathrm{~g} / \mathrm{Kg} \cdot \mathrm{d}$, Middle-dose group $15 \mathrm{~g} / \mathrm{Kg} \cdot \mathrm{d}$, and Low-dose group $7.5 \mathrm{~g} / \mathrm{Kg} \cdot \mathrm{d}$ ) groups. All groups were administrated for 7 days. The mice were killed after the third and last days. Viral load of lung tissues were observed by Real-time PCR. Pulmonary index and inhibition rate were calculated by formula. Furthermore, the mice macrophage Ana-1 was infected by FM1, treated with different decocting time YQP drug-containing serum for $24 \mathrm{~h}$. TLR3/4, MyD88, TRAF-6, TRAM and TRIF mRNA were detected by Real-time PCR. TLR3/4 proteins were observed by western blot.

Results: All YQP intervention groups induced a reduction in the viral load and pulmonary index on the third and last days of infection, especially in 3 minutes YQP H/M/L groups and 6 minutes High-dose group. Meanwhile, YQP intervention groups led to significant decrease in TLR3/4, MyD88, TRAF-6, TRAM and TRIF mRNA levels and TLR3/4 proteins, in particular with 3 and 6 minutes YQP groups. Conclusion: YQP could protect the lung tissue and alleviate the inflammation caused by influenza $A$ virus FM1. The optimal decoction time of YQP was 3to 6minutes on inhibit influenza A virus FM1 in mice.
\end{abstract}

Keywords: Yinqiao powder, Decoction time, Influenza A virus FM1, Toll-like receptor.

Accepted on March 22, 2017

\section{Introduction}

Influenza virus is a serious global health threat because of its significant mortality in humans, one of which is influenza a virus. It is an important pathogen of humans responsible for periodic pandemics and annual seasonal epidemics [1]. The first pandemic influenza a $(\mathrm{H} 1 \mathrm{~N} 1)$ of the $21^{\text {st }}$ century occurred unexpectedly in April 2009, which caused 18,449 laboratoryconfirmed deaths worldwide [2]. Due to the good adaptability and variation of influenza A virus, and the frequent emergence of drug resistant strains, no vaccine is available and the use of antiviral drugs is also complicated. In order to better cope with influenza virus, neuraminidase inhibitors such as Oseltamivir (Tamiflu) are promptly delivered to affected countries, where they play important roles in controlling the prevalence.
However, when a pandemic virus occurs is uncertain, so large antiviral stockpiles may lose effectiveness, thus resulting in massive economic burden. Traditional Chinese medicine (TCM), which has been commonly used in China for thousands of years, has long records of treating influenza virus and is beginning to play a more critical role in this field $[3,4]$.

YQP originated from Febrile Disease Differentiation, a classic works of TCM, which was written by Jutong Wu in Qing dynasty. As a famous multi-herb prescription in China, YQP is comprised of Flos Lonicerae Japonicae, Fructus Forsythiae, Radix Platycodonis, Radix Et Rhizoma Glycyrrhizae, Spica Schizonepetae, Semen Sojae Praeparatum, Fructus Arctii, Lophatherum Gracile, Mint and Rhizoma Phragmitis. Currently, clinical reports about YQP are increasing. It has been widely used in febrile infectious diseases and prevalence 
of influenza [5,6]. In the annotations, Jutong $\mathrm{Wu}$ wrote "as soon as the aroma comes out, start taking herbal, don't long time decoction". The key to get curative effect is decocting time [7]. But there is no quantitative standard until now, how long is aroma out and the exactly decocting time? Thus, this study aimed to determine the optimal decoction time of YQP on fight the prevalence of influenza.

\section{Materials and Methods}

\section{Animals}

Male BALB/c mice (18-20 g, SPF) were purchased from Beijing Vital River Laboratory Animal Technology Co., Ltd. (China, license number: SCXK (Jing) 2012-0001). Fifty male Sprague-Dowley (SD) rats were obtained from the Laboratory Animal Center, Hebei Medical University (China, license number: 1412004). They were all housed in a $12 \mathrm{~h}$ light/dark cycle and had access to the standard water and food ad libitum. The study experiments were conducted in accordance with the guidelines of the local Laboratory Animal Care Committee.

\section{Virus and cells}

Influenza A virus FM1 was provided by the National Institute for Viral Disease Control and Prevention (China). It was propagated in the allantoic cavity of embryonated eggs. The murine macrophage Ana-1 was obtained from the Cell Bank of the Chinese Academy of Sciences (Shanghai, China). Ana-1 cells were maintained in RPIM-1640 (Gibco, USA) medium with 10\% heat-inactivated fetal bovine serum (Hangzhou Sijiqing, China). The cells were kept in an incubator containing $5 \% \mathrm{CO}_{2}$ at $37^{\circ} \mathrm{C}$.

\section{Preparation of YQP decoction}

YQP, consisting of ten herbs, was provided by the TCM pharmacy of the Fourth Hospital of Hebei Medical University. All medicinal plants were pulverized to powder using a mechanical blender according to the original proportion. $50 \mathrm{~g}$, $100 \mathrm{~g}$, and $200 \mathrm{~g}$ of powder were prepared and boiled respectively for $3 \mathrm{mins}, 6 \mathrm{mins}$ and $12 \mathrm{mins}$ with $200 \mathrm{ml}$ of distilled water.

\section{Animal experiments}

After a $3 \mathrm{~d}$ acclimation period, the BALB/c mice $(\mathrm{N}=144)$ were random divided into twelve groups (blank control group, model control group, tamiflu $(27.5 \mathrm{mg} / \mathrm{Kg})$ group, $3 \mathrm{~min} Y \mathrm{YQ}$ (High-dose group $30 \mathrm{~g} / \mathrm{Kg} \cdot \mathrm{d}$, Middle-dose group $15 \mathrm{~g} / \mathrm{Kg} \cdot \mathrm{d}$, and Low-dose group $7.5 \mathrm{~g} / \mathrm{Kg} \cdot \mathrm{d}$ ) groups, 6 min YQP (Highdose group $30 \mathrm{~g} / \mathrm{Kg} \cdot \mathrm{d}$, Middle-dose group $15 \mathrm{~g} / \mathrm{Kg} \cdot \mathrm{d}$, and Low-dose group $7.5 \mathrm{~g} / \mathrm{Kg} \cdot \mathrm{d}$ ) groups, and $12 \mathrm{~min} \mathrm{YQP} \mathrm{(High-}$ dose group $30 \mathrm{~g} / \mathrm{Kg} \cdot \mathrm{d}$, Middle-dose group $15 \mathrm{~g} / \mathrm{Kg} \cdot \mathrm{d}$, and Low-dose group $7.5 \mathrm{~g} / \mathrm{Kg} \cdot \mathrm{d})$ groups $)(\mathrm{n}=12)$. In addition to the blank control group, all mice were slightly anesthetized by the inhalation of diethyl ether and intranasally infected with $15 \mathrm{LD}_{50} \mathrm{IV}$ FM1 $(0.05 \mathrm{~mL})$. After virus inoculation $24 \mathrm{~h}$, YQP groups were treated with different doses and decoction times of
YQP $(0.5 \mathrm{~mL})$ once daily for seven days. Tamiflu $(0.2 \mathrm{ml} / 10 \mathrm{~g})$ was given as a positive control group. Tamiflu was purchased from Roche Pharmaceutical (Shanghai, China). The blank and model control groups were injected with saline at the respective time points. Six mice per group were killed to obtain lung tissue on day 3 and 7 of treatment. The lung tissues were removed, weighed and preserved in liquid nitrogen. Viral load of lung tissues were observed by Real-time PCR. The pulmonary index and inhibition rate were calculated as: Pulmonary index=lung weight $(\mathrm{g}) /$ body weight $(\mathrm{g}) \times 100 \%$. Pulmonary index inhibition rate $=($ mean index of model control group - mean index of YQP-treated group)/mean index of model control group $\times 100 \%$.

\section{Preparation of YQP drug-containing serum}

Fifty male rats were divided into ten groups using a random number table with 5 rats in each group. YQP-treated groups (3 $\min \mathrm{YQP} H / \mathrm{M} / \mathrm{L}, 6 \mathrm{~min} \mathrm{YQP} H / \mathrm{M} / \mathrm{L}$, and $12 \mathrm{~min} \mathrm{YQP} \mathrm{H} / \mathrm{M} / \mathrm{L}$ groups) received gavage by twice every day (each $2 \mathrm{ml}$ ) for 5 days according to clinical equivalent dose of 10 times. Normal control group received the same volume of normal saline. Blood was obtained from the abdominal aorta at $1 \mathrm{~h}$ after the last intragastric administration, stored at $4{ }^{\circ} \mathrm{C}$ for $1 \mathrm{~h}$, and centrifuged at $3000 \mathrm{r} / \mathrm{min}$ for $15 \mathrm{~min}$. The serum was sterilized and inactivated at $56^{\circ} \mathrm{C}$ for $30 \mathrm{~min}$, followed by filtration through a $0.2 \mu \mathrm{m}$ mesh, and stored at $-20^{\circ} \mathrm{C}$.

\section{Cells studies}

Ana- 1 cells $\left(1 \times 10^{5}\right.$ cells $\left./ \mathrm{ml}\right)$ were cultured in 24 -well plastic plates for $24 \mathrm{~h}$ and inoculated with $0.5 \mathrm{ml}$ per well of influenza a virus FM1, except for normal control group. After $1 \mathrm{~h}$ for virus absorption, the solution was removed and replaced with 1 $\mathrm{ml}$ of medium containing different doses and decoction times of YQP serum. After incubation at $37^{\circ} \mathrm{C}$ for $24 \mathrm{~h}$, the solution was removed and the cells were collected for using subsequent tests.

\section{Quantitative real-time PCR}

Viral load of lung tissues and expression of six genes were observed by a quantitative real-time PCR assay. The GAPDH was used as an endogenous control. All primer sequences used in this study were list in Table 1. Total RNA was extracted from the lung tissues and Ana- 1 cells, and subsequently reverse transcribed to cDNA. qRT-PCR was performed on an ABI 7500 Real-Time PCR System (Applied Biosystems Life Technologies, USA). The PCR conditions were as follows: 10 min at $95^{\circ} \mathrm{C}$, followed by 40 cycles of $5 \mathrm{~s}$ at $95^{\circ} \mathrm{C}$, and $34 \mathrm{~s}$ at $60^{\circ} \mathrm{C}$. Gene expression levels were calculated using the $2^{\Delta \Delta \mathrm{Ct}}$ method.

Table 1. qRT-PCR Primers.

\begin{tabular}{lll}
\hline Gene & Primer & Sequence \\
\hline \multirow{2}{*}{ MyD88 } & PCR-F & CCA GAG TGG AAA GCA GTG TC \\
\cline { 2 - 3 } & PCR-R & GTC CTT CTT CAT CGC CTT GT \\
\hline
\end{tabular}




\begin{tabular}{|c|c|c|}
\hline \multirow{2}{*}{ TLR3 } & PCR-F & AGTGCCGTCTATTTGCCACACA \\
\hline & PCR-R & AACAGTGCACTTGGTGGTGGAG \\
\hline \multirow{2}{*}{ TLR4 } & PCR-F & ATT CCT GCA GTG GGT CAAGG \\
\hline & PCR-R & ACA ATT CCA CCT GCT GCC TC \\
\hline \multirow{2}{*}{ TRAF-6 } & PCR-F & ATAAGGGATGCAGGTCACAAATG \\
\hline & PCR-R & TCCTCAAGATGTCTCAGTTCCAT \\
\hline \multirow{2}{*}{ TRIF } & PCR-F & CCACGTCCTACATCTGCAGCTACCA \\
\hline & PCR-R & AACAGCATCTGCAGCTACCA \\
\hline \multirow{2}{*}{ TRAM } & PCR-F & ATAAGTGCCCCCTTTCTTCT \\
\hline & PCR-R & CCTCGTCGGTGTCATCTTCT \\
\hline \multirow{2}{*}{ FM1 } & PCR-F & GAGAAAGAAGTCCTTGTGC \\
\hline & PCR-R & TCTATCATTCCAGTCCATCCC \\
\hline \multirow{2}{*}{ GAPDH } & PCR-F & AAGGTGAAGGTCGGAGTCAAC \\
\hline & PCR-R & GGGGTCATTGATGGCAACAATA \\
\hline
\end{tabular}

\section{Western blotting}

TLR3/4 proteins were observed by western blot. Total extracted protein lysates from Ana-1 cells were prepared by standard procedures, and protein concentration was determined by BCA protein assay kit (Beyotime, Shanghai, China). $50 \mu \mathrm{g}$ of protein per lane was separated by $10-12 \%$ SDS-PAGE, and transferred onto PVDF membranes. The membrane was incubated with the TLR3, TLR 4 or $\beta$-actin antibody (Santa Cruz Biotechnology, USA), and detected by the Odyssey twocolor infrared imaging system.

\section{Statistical analysis}

All statistical analyses were carried out using Statistical Analysis System V8 (SAS Institute Inc. USA). Data were presented as Mean $\pm \mathrm{SD}$. Multiple comparisons between groups were performed using one-way analysis of variance (ANOVA) followed by the Bonferroni correction, and $\mathrm{P}<0.05$ was considered statistically significant.

\section{Results}

\section{Effects of different YQP-treated groups in vivo}

Influenza a virus FM1 leads to high lung viral load and pneumonia, so the efficacy of treatment was evaluated on the pulmonary index, inhibition rate of index and viral load. The statistical analysis showed that different YQP-treated groups displayed a protective effect on FM1 mice. Compared with model control group, YQP-treated groups (6 min High-dose group, and $3 \mathrm{~min} \mathrm{YQP} \mathrm{H} / \mathrm{M} / \mathrm{L}$ ) significantly reduced the pulmonary index on the third day after infection $(\mathrm{P}<0.05)$, and inhibition rate of lung index was $21.53 \%, 24.17 \%, 21.57 \%$, and $22.59 \%$, respectively. In the YQP-treated groups, compared with 12 min groups, the above four groups had statistical significance. There was no difference compared with tamiflu group. On the last day after infection, the pulmonary index was reduced in all YQP-treated groups, especially in 3 min High-dose group. Inhibition rate of 3 min High-dose group was $30.34 \%$, compared with $32.92 \%$ in tamiflu group, had equivalent efficacy (Tables 2A and 2B).

Table 2A. Different YQP-treated groups displayed a protective effect on FM1 mice (the third day).

\begin{tabular}{llll}
\hline Group ( $\mathbf{n}=6)$ & Pulmonary index & \multicolumn{1}{c}{$\begin{array}{c}\text { Pulmonary index } \\
\text { inhibition (\%) }\end{array}$} \\
\hline blank control group & $0.62 \pm 0.05^{*}$ & - \\
\hline model control group & $1.14 \pm 0.09$ & - \\
\hline Tamiflu group & $0.87 \pm 0.06^{*}$ & 23.29 \\
\hline \multirow{3}{*}{12 min } & low-concentration & $1.03 \pm 0.01$ & 8.87 \\
\cline { 2 - 4 } & mid-concentration & $1.01 \pm 0.08$ & 11.30 \\
\cline { 2 - 4 } & high-concentration & $1.02 \pm 0.01$ & 10.38 \\
\hline \multirow{3}{*}{6 min } & low-concentration & $0.98 \pm 0.13$ & 13.47 \\
\cline { 2 - 4 } & mid-concentration & $0.94 \pm 0.07$ & 17.04 \\
\cline { 2 - 4 } & high-concentration & $0.89 \pm 0.19^{*}$ & 21.53 \\
\hline 3 min & low-concentration & $0.88 \pm 0.05^{*} \#$ & 22.59 \\
\cline { 2 - 4 } & mid-concentration & $0.89 \pm 0.03^{*} \#$ & 21.57 \\
\cline { 2 - 4 } & high-concentration & $0.86 \pm 0.03^{*} \#$ & 24.17 \\
\hline
\end{tabular}

${ }^{*} \mathrm{P}<0.05$ compared with model control group. In the YQP-treated groups, $\# \mathrm{P}<0.05$ compared with 12 min groups.

Table $2 B$. Different $Y Q P$-treated groups displayed a protective effect on FM1 mice (the last day).

\begin{tabular}{llll}
\hline Group (n=6) & Pulmonary index & $\begin{array}{l}\text { Pulmonary } \\
\text { inhibition (\%) }\end{array}$ \\
\hline blank control group & $0.59 \pm 0.03^{*}$ & - \\
\hline model control group & $1.87 \pm 0.45$ & - \\
\hline Tamiflu group & $1.26 \pm 0.20^{*}$ & 32.92 \\
\hline \multirow{3}{*}{12 min } & low-concentration & $1.57 \pm 0.20^{*}$ & 16.25 \\
\cline { 2 - 4 } & mid-concentration & $1.55 \pm 0.07^{*}$ & 17.07 \\
\cline { 2 - 4 } & high-concentration & $1.55 \pm 0.14^{*}$ & 17.39 \\
\hline \multirow{3}{*}{6 min } & low-concentration & $1.46 \pm 0.19^{*}$ & 22.08 \\
\cline { 2 - 4 } & mid-concentration & $1.44 \pm 0.15^{*}$ & 23.23 \\
\cline { 2 - 4 } & high-concentration & $1.40 \pm 0.12^{*}$ & 25.25 \\
\hline \multirow{3}{*}{3 min } & low-concentration & $1.37 \pm 0.14^{*}$ & 27.13 \\
\cline { 2 - 4 } & mid-concentration & $1.33 \pm 0.24^{*}$ & 28.98 \\
\cline { 2 - 4 } & high-concentration & $1.31 \pm 0.42^{*}$ & 30.34 \\
\hline
\end{tabular}

${ }^{*} \mathrm{P}<0.05$ compared with model control group. No difference between YQPtreated groups.

Viral load of lung tissues were observed by Real-time PCR. The results showed that YQP could reduce viral load in all 
treatment groups on the third and last day after infection $(\mathrm{P}<0.05)$. There was no significantly difference compared with tamiflu group. In the YQP-treated groups, compared with 12 min the same dose group, every dosage of $3 \mathrm{~min}$ and $6 \mathrm{~min}$ groups had reduced on the last day, especially in 3 min Highdose group $(72.66 \% ; 537111.33 \pm 51527.89)$. Protective effect was found in all YQP-treated groups, and the degrees of protection were different depending on the decoction time (Tables $3 \mathrm{~A}$ and $3 \mathrm{~B}$ ).

Table 3A. Effects of YQP-treated groups on viral load (the third day).

\begin{tabular}{|c|c|c|c|}
\hline \multicolumn{2}{|c|}{ Group (n=6) } & Viral load & Inhibition (\%) \\
\hline \multicolumn{2}{|c|}{ blank control group } & - & - \\
\hline \multicolumn{2}{|c|}{ model control group } & $28059.33 \pm 9032.42$ & - \\
\hline \multicolumn{2}{|c|}{ Tamiflu group } & $12058.00 \pm 2940.84^{*}$ & 57.03 \\
\hline \multirow[t]{3}{*}{$12 \mathrm{~min}$} & low-concentration & $20868.67 \pm 8510.34^{*}$ & 25.63 \\
\hline & mid-concentration & $19873.50 \pm 8691.19^{*}$ & 29.17 \\
\hline & high-concentration & $20161.00 \pm 8231.43^{*}$ & 28.15 \\
\hline \multirow[t]{3}{*}{$6 \min$} & low-concentration & $18801.50 \pm 7285.16^{*}$ & 32.99 \\
\hline & mid-concentration & $16707.50 \pm 6535.86^{*}$ & 40.46 \\
\hline & high-concentration & $17757.17 \pm 7049.35^{*} \# \Delta$ & 36.72 \\
\hline \multirow[t]{3}{*}{$3 \min$} & low-concentration & $15119.00 \pm 5075.64^{*} \# \Delta$ & 46.71 \\
\hline & mid-concentration & $14350.83 \pm 4949.68^{* \# \Delta}$ & 48.86 \\
\hline & high-concentration & $14034.83 \pm 4409.83^{* \# \Delta}$ & 49.98 \\
\hline
\end{tabular}

${ }^{*} \mathrm{P}<0.05$ compared with model control group. In the YQP-treated groups, ${ }^{\#} \mathrm{P}<0.05$ compared with $12 \mathrm{~min}$ the same dose group, $\triangle \mathrm{P}<0.05$ compared with $6 \mathrm{~min}$ the same dose group.

Table 3B. Effects of YQP-treated groups on viral load (the last day).

\begin{tabular}{llll}
\hline Group $(\mathbf{n}=6)$ & Viral load & \multicolumn{1}{l}{$\begin{array}{l}\text { Inhibition } \\
(\%)\end{array}$} \\
\hline blank control group & - & - \\
\hline model control group & $1964362.67 \pm 197008.62$ & - \\
\hline Tamiflu group & $515668.50 \pm 68434.34^{*}$ & 73.75 \\
\hline \multirow{3}{*}{12 min } & low-concentration & $1258829.83 \pm 387044.23^{* \#}$ & 35.92 \\
\cline { 2 - 4 } & mid-concentration & $1200039.33 \pm 188136.68^{* \#}$ & 38.91 \\
\cline { 2 - 4 } & high-concentration & $975541.33 \pm 112000.67^{\star \#}$ & 50.34 \\
\hline \multirow{3}{*}{6 min } & low-concentration & $1005029.67 \pm 75781.29^{*} \Delta$ & 48.84 \\
\cline { 2 - 4 } & mid-concentration & $794515.50 \pm 117875.53^{*} \Delta$ & 59.55 \\
\cline { 2 - 4 } & high-concentration & $596549.83 \pm 88597.50^{*} \Delta$ & 69.63 \\
\hline 3 min & low-concentration & $638064.17 \pm 60221.34^{*} \Delta^{\#}$ & 67.52 \\
\cline { 2 - 4 } & mid-concentration & $566836.00 \pm 73037.67^{*} \Delta^{\#}$ & 71.14 \\
\cline { 2 - 4 } & high-concentration & $537111.33 \pm 51527.89^{*} \Delta$ & 72.66 \\
\hline
\end{tabular}

${ }^{*} \mathrm{P}<0.05$ compared with model control group. In the YQP-treated groups, $\triangle \mathrm{P}<0.05$ compared with $12 \mathrm{~min}$ the same dose group, ${ }^{\#} \mathrm{P}<0.05$ compared with $6 \mathrm{~min}$ the same dose group.

\section{Effects of different YQP-treated groups in vitro}

Ana-1 cells were successfully infected with influenza A virus FM1 and incubated in medium with YQP serum containing various decoction times and doses for $24 \mathrm{~h}$. It was shown that YQP serum decreased the expression of TLR4/MyD88 dependent and non-dependent pathway (Tables 4A and 4B). Compared with blank control group, the expression of TLR4/ MyD88/TRAF-6 and TLR3/TRAM/TRIF in model control group was significantly increased $(\mathrm{P}<0.05)$. YQP intervention groups reduced the expression of TLR4/MyD88/TRAF- 6 and TLR3/TRAM/TRIF, especially in $3 \mathrm{~min}$ groups and $6 \mathrm{~min}$ High-dose group $(\mathrm{P}<0.05)$. Thus, we further assessed the protein levels of TLR3/4 by western blot. The data showed that TLR3 protein level in $6 \mathrm{~min}$ Middle-dose group was significantly down-regulated $(\mathrm{P}<0.05,0.232 \pm 0.059)$. Meanwhile, compared with model control group, TLR4 protein level was significantly down-regulated in $3 \mathrm{~min}$ and $6 \mathrm{~min}$ groups $(\mathrm{P}<0.05)$ (Table 5 and Figure 1$)$. In the YQP intervention groups, compared with $12 \mathrm{~min}$ the same dose group, 3 min High-dose group and 6 min YQP H/M groups significantly decreased the protein expression of TLR4 $(0.276$ $\pm 0.021,0.250 \pm 0.019$, and $0.269 \pm 0.017$, respectively).

Table 4A. Effects of YQP serum on TLR4/MyD88 dependent pathway.

\begin{tabular}{|c|c|c|c|c|}
\hline \multicolumn{2}{|l|}{ Group } & TLR4 & MyD88 & TRAF-6 \\
\hline \multicolumn{2}{|c|}{ blank control group } & $1.021 \pm 0.011^{*}$ & $1.072 \pm 0.058^{*}$ & $1.031 \pm 0.037^{*}$ \\
\hline \multicolumn{2}{|c|}{ model control group } & $3.899 \pm 0.092$ & $3.807 \pm 0.069$ & $4.055 \pm 0.150$ \\
\hline \multirow{3}{*}{$12 \mathrm{~min}$} & low-concentration & $3.453 \pm 0.080^{*}$ & $3.479 \pm 0.058^{*}$ & $3.652 \pm 0.093^{*}$ \\
\hline & mid-concentration & $3.425 \pm 0.077^{*}$ & $3.300 \pm 0.086^{*}$ & $3.611 \pm 0.077^{\star}$ \\
\hline & $\begin{array}{l}\text { high- } \\
\text { concentration }\end{array}$ & $3.406 \pm 0.073^{*}$ & $3.201 \pm 0.077^{*}$ & $3.601 \pm 0.115^{\star}$ \\
\hline \multirow{3}{*}{$6 \min$} & low-concentration & $3.233 \pm 0.124^{*}$ & $3.089 \pm 0.102^{*}$ & $3.471 \pm 0.073^{*}$ \\
\hline & mid-concentration & $3.146 \pm 0.174^{*}$ & $2.868 \pm 0.099^{*}$ & $3.297 \pm 0.091^{*}$ \\
\hline & $\begin{array}{l}\text { high- } \\
\text { concentration }\end{array}$ & $2.919 \pm 0.086^{*}$ & $2.770 \pm 0.167^{*}$ & $3.008 \pm 0.106^{*}$ \\
\hline \multirow{3}{*}{$3 \min$} & low-concentration & $2.799 \pm 0.111^{*}$ & $2.386 \pm 0.063^{* \Delta}$ & $2.897 \pm 0.102^{*}$ \\
\hline & mid-concentration & $2.237 \pm 0.094^{\star \Delta}$ & $2.195 \pm 0.068^{* \Delta}$ & $2.424 \pm 0.098^{* \Delta}$ \\
\hline & $\begin{array}{l}\text { high- } \\
\text { concentration }\end{array}$ & $2.194 \pm 0.125^{*} \Delta$ & $2.121 \pm 0.092^{*} \Delta$ & $2.380 \pm 0.057^{*} \Delta$ \\
\hline
\end{tabular}

${ }^{*} \mathrm{P}<0.05$ compared with model control group. In the YQP-treated groups, ${ }^{\Delta} \mathrm{P}<0.05$ compared with $12 \mathrm{~min}$ the same dose group.

Table 4B. Effects of YQP serum on TLR4/MyD88 non-dependent pathway.

\begin{tabular}{llll}
\hline Group & TLR3 & TRAM & TRIF \\
\hline blank control group & $1.018 \pm 0.007^{*}$ & $1.043 \pm 0.041^{*}$ & $1.059 \pm 0.043^{*}$ \\
\hline
\end{tabular}




\begin{tabular}{|c|c|c|c|c|}
\hline \multicolumn{2}{|c|}{ model control group } & \multirow{2}{*}{$\begin{array}{l}3.845 \pm 0.086 \\
3.349 \pm 0.069^{*}\end{array}$} & \multirow{2}{*}{$\begin{array}{l}3.786 \pm 0.319 \\
3.394 \pm 0.175^{*}\end{array}$} & \multirow{2}{*}{$\begin{array}{l}4.018 \pm 0.144 \\
3.422 \pm 0.125^{*}\end{array}$} \\
\hline \multirow{3}{*}{$12 \mathrm{~min}$} & $\begin{array}{l}\text { low- } \\
\text { concentration }\end{array}$ & & & \\
\hline & $\begin{array}{l}\text { mid- } \\
\text { concentration }\end{array}$ & $3.324 \pm 0.045^{*}$ & $3.279 \pm 0.167^{*}$ & $3.258 \pm 0.155^{*}$ \\
\hline & $\begin{array}{l}\text { high- } \\
\text { concentration }\end{array}$ & $3.293 \pm 0.024^{*}$ & $3.108 \pm 0.127^{*}$ & $3.077 \pm 0.122^{*}$ \\
\hline \multirow{3}{*}{$6 \mathrm{~min}$} & $\begin{array}{l}\text { low- } \\
\text { concentration }\end{array}$ & $3.133 \pm 0.052^{*}$ & $2.836 \pm 0.105^{*}$ & $2.993 \pm 0.170^{*}$ \\
\hline & $\begin{array}{l}\text { mid- } \\
\text { concentration }\end{array}$ & $3.076 \pm 0.063^{*}$ & $2.690 \pm 0.129^{*}$ & $2.746 \pm 0.099^{*}$ \\
\hline & $\begin{array}{l}\text { high- } \\
\text { concentration }\end{array}$ & $2.921 \pm 0.055^{*} \Delta$ & $2.573 \pm 0.075^{*}$ & $2.503 \pm 0.100^{*} \Delta$ \\
\hline \multirow{3}{*}{$3 \mathrm{~min}$} & $\begin{array}{l}\text { low- } \\
\text { concentration }\end{array}$ & $2.847 \pm 0.066^{*} \Delta$ & $2.333 \pm 0.097^{* \Delta}$ & $2.301 \pm 0.127^{* \Delta}$ \\
\hline & $\begin{array}{l}\text { mid- } \\
\text { concentration }\end{array}$ & $2.255 \pm 0.044^{*}$ & $2.128 \pm 0.126^{\star}$ & $2.000 \pm 0.199^{*}$ \\
\hline & $\begin{array}{l}\text { high- } \\
\text { concentration }\end{array}$ & $2.157 \pm 0.049^{*}$ & $1.996 \pm 0.141^{*}$ & $1.925 \pm 0.229^{*}$ \\
\hline
\end{tabular}

${ }^{*} \mathrm{P}<0.05$ compared with model control group. In the YQP-treated groups, ${ }^{\Delta} \mathrm{P}<0.05$ compared with $12 \mathrm{~min}$ the same dose group.

\section{Discussion}

Influenza virus, one of the major pandemic diseases around the world, is a serious public health problem. At present, only M2 proton channel blockers and neuraminidase inhibitors (amantadine and oseltamivir) are used in clinic to against the virus. It brought a massive economic burden. Furthermore, evidence shows that influenza virus is becoming resistant to these drugs [8-10]. TCM, is safe, effective, and low cost, has been commonly used to prevention and treatment of various diseases for thousands of years. YQP, a traditional Chinese medicine applied to anemopyretic cold, has been found to possess potent action against influenza based on principles of evidence-based medicine [11]. Beijing Chao-Yang Hospital investigated the efficacy of YQP in the treatment of H1N1 influenza infection. 410 patients with mild symptoms sought to examine the fever-reducing action of YQP. The results showed that patients treated with YQP had a fever for $16 \mathrm{~h}$, and with oseltamivir had a fever for $20 \mathrm{~h}$. Thus, YQP was able to effectively shorter the duration of fever in patients with influenza infection [12]. But this study did not clarify the specific decoction time of YQP.

Table 5. Effects of YQP serum on TLR3/4 protein expression.

\begin{tabular}{llll}
\hline Group & TLR3/ $\beta$-actin & TLR4/ $\beta$-actin \\
\hline model control group & $0.771 \pm 0.028$ & $0.685 \pm 0.018$ \\
\hline \multirow{2}{*}{$3 \mathrm{~min}$} & low-concentration & $0.801 \pm 0.012$ & $0.305 \pm 0.019^{*}$ \\
\cline { 2 - 4 } & mid-concentration & $0.712 \pm 0.020$ & $0.291 \pm 0.012^{*}$ \\
\cline { 2 - 4 } & high-concentration & $0.770 \pm 0.024$ & $0.276 \pm 0.021^{*} \Delta$ \\
\hline 6 min & low-concentration & $0.789 \pm 0.022$ & $0.333 \pm 0.029^{*}$ \\
\hline
\end{tabular}

\begin{tabular}{llll}
\hline & mid-concentration & $0.232 \pm 0.059^{*}$ & $0.269 \pm 0.017^{\Delta}$ \\
\cline { 2 - 4 } & high-concentration & $0.741 \pm 0.024$ & $0.250 \pm 0.019^{*} \Delta$ \\
\hline \multirow{3}{*}{$12 \mathrm{~min}$} & low-concentration & $0.744 \pm 0.032$ & $0.562 \pm 0.024$ \\
\cline { 2 - 4 } & mid-concentration & $0.640 \pm 0.050$ & $0.667 \pm 0.047$ \\
\cline { 2 - 4 } & high-concentration & $0.650 \pm 0.026$ & $0.597 \pm 0.027$
\end{tabular}

${ }^{*} \mathrm{P}<0.05$ compared with model control group. In the YQP-treated groups, ${ }^{\triangle} \mathrm{P}<0.05$ compared with $12 \mathrm{~min}$ the same dose group.

Our results also indicated that the inhibitory activity of YQP against influenza A virus FM1 in vivo and in vitro. Different YQP-treated groups displayed a protective effect on FM1 mice. The 6 min High-dose group and 3 min each dose groups significantly reduced the pulmonary index and inhibition rate on the third day after infection. On the last day, inhibition rate of 3 min High-dose group was 30.34\%, compared with $32.92 \%$ in tamiflu group, had equivalent efficacy. According to our results, YQP could reduce viral load of lung tissue in all treatment groups and no significantly difference compared with tamiflu group. Compared with 12 min the same dose group, every dosage of $3 \mathrm{~min}$ and $6 \mathrm{~min}$ groups had obviously reduced. The degrees of anti-influenza virus were different depending on the decoction time.

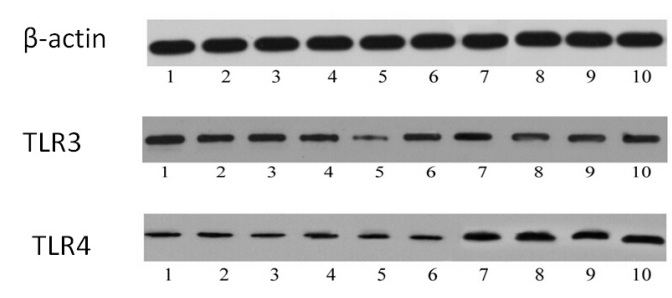

Figure 1. Effects of YQP serum on TLR3/4 protein expression. Note: (1) 3 min low-concentration group, (2) 3 min mid-concentration group, (3) $3 \mathrm{~min}$ high-concentration group, (4) $6 \mathrm{~min}$ lowconcentration group, (5) 6 min mid-concentration group, (6) 6 min high-concentration group, (7) 12 min low-concentration group, (8) 12 min mid-concentration group, (9) $12 \mathrm{~min}$ high-concentration group, (10) model control group.

Influenza A virus is a single-stranded RNA virus that causes severe respiratory tract infection, especially for elderly individuals and immunocompromised patients [13,14]. Tolllike receptor (TLR) plays a critical role in the innate immune system. TLR4 is activated during influenza A virus infection, and is a key contributor to exacerbation of disease. Both TLR4/ MyD88 dependent pathway (TLR4/MyD88/TRAF-6) and MyD88 independent pathway (TLR3/TRAM/TRIF) may play important roles in inflammation and disease caused by virus infection [15-18]. Kegan Liyan oral liquid (KGLY), a Chinese prescription modified from classic formulas YQP and Shen Jie San, may be a potential therapeutic agent for acute lung injury due to suppression of oxidative stress and inflammatory response, inhibition of TLR4-mediated NF- $\mathrm{KB}$ activation, and down-regulation of MMP9 expression [19]. Furthermore, it was reported that Yinhuapinggan granule, a Chinese medicine 
based on Ma Huang Tang, has antiviral effects in IFV-infected mice, which is associated with the inhibition of the TLR4MyD88-TRAF6 signal pathway. The results cited thus far indicate that TCM has a very well antiviral effect [20]. These findings suggest that YQP serum intervention groups decreased the expression of TLR4/MyD88/TRAF-6 and TLR3/ TRAM/TRIF pathway, especially in $3 \mathrm{~min}$ groups and $6 \mathrm{~min}$ High-dose group.

\section{Conclusions}

We concluded that 3 to $6 \mathrm{~min}$ of decoction time is more effective in inhibiting the influenza virus and more likely to be the optimal decoction time of YQP for clinical use. However, these findings are preliminary, and the special mechanism of different decoction time of YQP will need to be further investigated.

\section{Acknowledgment}

This work was supported by grants from the National Natural Science Foundation of China (no.81202679)

\section{References}

1. Vasin AV, Petrova AV, Egorov VV. The influenza A virus NS genome segment displays lineage-specific patterns in predicted RNA secondary structure. BMC Res Notes 2016; 9: 279-285.

2. Hurt AC, Kelly H. Debate Regarding Oseltamivir Use for Seasonal and Pandemic Influenza. Emerg Infect Dis 2016; 22: 949-955.

3. Wolf $\mathrm{S}, \mathrm{Wu} \mathrm{W}$, Jones C. MicroRNA Regulation of Human Genes Essential for Influenza A (H7N9) Replication. PLOS ONE 2016; 11: e0155104.

4. Xu G, Dou J, Zhang L, Guo Q, Zhou C. Inhibitory Effects of Baicalein on the Influenza Virus in Vivo Is Determined by Baicalin in the Serum. Biol Pharmaceut Bulletin 2010; 33: 238-243.

5. Tao Z, Yang Y, Shi W. Complementary and alternative medicine is expected to make greater contribution in controlling the prevalence of influenza. BioScience Trends 2013; 7: 253-256.

6. Shu Y, Chen Y, Qin K, Liu X, Cai B. A Study on the Chemical Compositions of the Yinqiaosan (Lonicerae and Forsythiae Powder) at Different Time of Later-decoction by Gas Chromatography Mass Spectrometry. Pharmacognosy Magazine 2016; 12: 134-138.

7. Tang W. Upper energizer diseases. Febrile Dis Differentiat 2005; 1: 17-19.

8. Spelmink L, Sender V, Hentrich K. Toll-Like Receptor 3/ TRIF-Dependent IL-12p70 Secretion Mediated by Streptococcus pneumoniae RNA and Its Priming by Influenza A Virus Coinfection in Human Dendritic Cells. MBio 2016; 7: e00168.

9. Goff PH, Hayashi T, Martínez-Gil L. Synthetic Toll-Like Receptor 4 (TLR4) and TLR7 Ligands as Influenza Virus
Vaccine Adjuvants Induce Rapid, Sustained, and Broadly Protective Responses. J Virol 2015; 89: 3221-3235.

10. Davison VE, Sanford BA. Adherence of Staphylococcus aureus to Influenza A Virus-Infected Madin-Darby Canine Kidney Cell Cultures. Infect Immun 1981; 32: 118-126.

11. Ge H, Wang YF, Xu J. Anti-influenza agents from Traditional Chinese Medicine. Nat Product Rep 2010; 27: 1758-1780.

12. Wang C, Cao B, Liu QQ. Oseltamivir Compared With the Chinese Traditional Therapy Maxingshigan-Yinqiaosan in the Treatment of H1N1 Influenza: A Randomized Trial. Ann Int Med 2011; 155: 217-225.

13. Wohlbold TJ, Krammer F. In the Shadow of Hemagglutinin: A Growing Interest in Influenza Viral Neuraminidase and Its Role as a Vaccine Antigen. Viruses 2014; 6: 2465-2494.

14. Ropero-Álvarez AM, Kurtis HJ, Danovaro-Holliday MC, Ruiz-Matus C, Andrus JK. Expansion of seasonal influenza vaccination in the Americas. BMC Public Health 2009; 9: 361.

15. Shirey KA, Lai W, Scott AJ, Lipsky M, Mistry P, Pletneva LM, Karp CL, McAlees J, Gioannini TL, Weiss J, Chen WH, Ernst RK, Rossignol DP, Gusovsky F, Blanco JC, Vogel SN. The TLR4 antagonist Eritoran protects mice from lethal influenza infection. Nature 2013; 497: 498-502.

16. Piao W, Shirey KA, Ru LW, Lai W, Szmacinski H, Snyder GA, Sundberg EJ, Lakowicz JR, Vogel SN, Toshchakov VY. A Decoy Peptide that Disrupts TIRAP Recruitment to TLRs Is Protective in a Murine Model of Influenza. Cell Rep 2015; 11: 1941-1952.

17. Tsai SY, Segovia JA, Chang TH. DAMP Molecule S100A9 Acts as a Molecular Pattern to Enhance Inflammation during Influenza A Virus Infection: Role of DDX21-TRIFTLR4-MyD88 Pathway. PLoS Pathogens 2014; 10: e1003848.

18. Tanaka A, Nakamura S, Seki M. Toll-Like Receptor 4 Agonistic Antibody Promotes Innate Immunity against Severe Pneumonia Induced by Coinfection with Influenza Virus and Streptococcus pneumonia. Clin Vaccine Immunol 2013; 20: 977-985.

19. Zhang X, Sun CY, Zhang YB. Kegan Liyan oral liquid ameliorates lipopolysaccharide-induced acute lung injury through inhibition of TLR4-mediated NF-kB signaling pathway and MMP-9 expression. J Ethnopharmacol 2016; 186: 91-102.

20. Peng XQ, Zhou HF, Zhang YY. Antiviral effects of Yinhuapinggan granule against influenza virus infection in the ICR mice model. J Nat Med 2016; 70: 75-88.

\section{*Correspondence to}

Bingjie Huo

Department of Traditional Chinese Medicine

Fourth Hospital of Hebei Medical University

PR China 